\title{
High concentrations of fatty acids and $\beta$-hydroxybutyrate impair the growth hormone-mediated hepatic JAK2-STAT5 pathway in clinically ketotic cows
}

\author{
Xiliang Du, Yiwei Zhu, Zhicheng Peng, Yuanxu Cui, Qiang Zhang, Zhen Shi, Yuan Guan, Xueying Sha, \\ Taiyu Shen, Yuchen Yang, Xiaobing Li, Zhe Wang, Xinwei Li, ${ }^{1}$ and Guowen Liu ${ }^{1}$ \\ Key Laboratory of Zoonosis, Ministry of Education, College of Veterinary Medicine, Jilin University, 5333 Xi'an Road, Changchun, \\ 130062, Jilin, China
}

\section{ABSTRACT}

The hepatic growth hormone (GH)-insulin-like growth factor (IGF)-I axis is essential for regulating intrahepatic lipid metabolism. Ketotic cows are characterized by high blood concentrations of fatty acids and $\beta$-hydroxybutyrate (BHB), which display lipotoxicity. The aim of this study was to investigate changes in the hepatic GH-IGF-I axis in ketotic cows and to determine the effects of fatty acids and BHB on the GH-IGF-I axis in calf hepatocytes. Liver and blood samples were collected from healthy $(\mathrm{n}=15)$ and clinically ketotic $(\mathrm{n}=15)$ cows. Hepatocytes were isolated from calves and treated with various concentrations of GH, fatty acids, and BHB. The results showed that clinically ketotic cows displayed a high blood concentration of $\mathrm{GH}$, a low blood concentration of IGF-I, and decreased hepatic GHR1A expression as well as impaired hepatic Janus kinase 2 (JAK2)-signal transducer and activator of transcription 5 (STAT5) signaling. In vitro, $\mathrm{GH}$ treatment induced activation of the JAK2-STAT5 pathway to increase the mRNA expression and secretion of IGF-I in calf hepatocytes. More importantly, treatment with fatty acids or BHB significantly inhibited GHR1A mRNA and JAK2 protein expression, as well as the STAT5 phosphorylation level and phospho-STAT5 nuclear translocation; these effects markedly reduced $I G F 1$ mRNA expression and secretion in calf hepatocytes. In summary, these results indicate that high blood concentrations of fatty acids or BHB can impair the intrahepatic GH-mediated JAK2STAT5 pathway and downregulate IGF-I expression and secretion in ketotic cows.

Key words: ketotic cows, growth hormone, insulinlike growth factor-I

\footnotetext{
Received May 25, 2017.

Accepted November 27, 2017.

${ }^{1}$ Corresponding authors:
} lixinwei100@126.com liuguowen2008@163.com and

\section{INTRODUCTION}

During the early lactation period, most dairy cows experience a negative energy balance (NEB) caused by decreased DMI and increased demand for energy to support milk production (Xu et al., 2015a,b). Severe NEB initiates fat mobilization and a subsequent increase in the blood concentrations of fatty acids and BHB (Liu et al., 2014), which may result in the development of ketosis and fatty liver. Neuroendocrine responses involving the hypothalamus-pituitary-liver axis may result in significant changes in the secretion of several hormones, including prolactin and growth hormone (GH; Elsasser et al., 2000). These hormones are believed to have a profound effect on the adaptation to NEB (Herdt, 2000). Interestingly, postpartum dairy cows with NEB display GH resistance, high blood concentration of GH, and low blood concentration of IGF-I (Radcliff et al., 2006).

Growth hormone is a pituitary hormone that directly or indirectly affects numerous aspects of animal lactation, growth, and reproduction (Lucy et al., 2001; Douglas et al., 2016; Geiger et al., 2016). Hepatocytes are the target cells of GH and are the main source of IGF-I (Thissen et al., 1994; Sheehy et al., 2017). Growth hormone binds growth hormone receptor (GHR), thereby activating Janus kinase 2 (JAK2)-signal transducer and activator of transcription 5 (STAT5) signaling pathways and increasing the expression and synthesis of IGF-I in hepatocytes (Barclay et al., 2011). Furthermore, IGF-I acts as an endocrine factor that controls GH secretion through a negative feedback loop (Le Roith et al., 2001). Therefore, low hepatic expression of GHR could lead to decreased liver IGF-I production and less GH negative feedback (Silva et al., 2017).

The hepatic GH-IGF-I axis is essential in the regulation of intrahepatic lipid metabolism and mammary milk production (Piechotta et al., 2012; Mense et al., 2015; Silva et al., 2015). Studies have shown that dairy cows display downregulated hepatic GHR, increased blood GH concentration, and decreased blood IGF-I 
Table 1. Nutrient composition of the diets

\begin{tabular}{lc}
\hline Item & Measurement \\
\hline Ingredient (\%) & \\
Corn silage & 40.00 \\
Corn & 35.00 \\
Wheat bran & 8.00 \\
Soybean meal & 5.00 \\
Sunflower & 8.00 \\
NaCl & 1.00 \\
Premix ${ }^{1}$ & 1.80 \\
NaHCO & 1.20 \\
Total & 100.00 \\
Nutrient composition (\% of DM) & \\
NE (MJ/kg) $_{\text {CP }}$ & 6.70 \\
NDF & 15.20 \\
ADF & 33.45 \\
NFC & 17.20 \\
Ca & 40.40 \\
P & 0.70 \\
\hline
\end{tabular}

${ }^{1}$ The premix provided the following per $\mathrm{kg}$ of diet: vitamin A 200,000 IU, vitamin D 70,000 IU, vitamin E 1,000 IU, Fe 2,000 mg, Cu $600 \mathrm{mg}$, Zn 2,400 mg, Mn 1,300 mg, I 6 mg, Co 7 mg.

concentration during the first week of lactation compare with prepartum period (Lucy et al., 2001; BernierDodier et al., 2011; Gross et al., 2011). Additionally, Fenwick et al. (2008) demonstrated that plasma protein and hepatic mRNA for IGF-I were reduced in cows with severe NEB induced by feed restriction on the second day of lactation compared with cows with mild NEB (Fenwick et al., 2008). Thus, these studies demonstrated that the GH-IGF-I axis is uncoupled in earlylactating cows.

Lipotoxicity is defined as lipid- and lipid metaboliteinduced lean tissue dysfunction (Erikci and Hotamisligil, 2016). Dairy cows with clinical ketosis display high blood concentrations of fatty acids and BHB. Lucy et al. (2001) reported that GH resistance further promoted lipolysis in adipose tissue and was associated with an increase in fatty acid concentration in the blood during lactation (Lucy et al., 2001). Our previous studies indicated that fatty acids and BHB displayed lipotoxicity in liver tissues (Shi et al., 2014; Song et al.,
2014; Deng et al., 2015; Song et al., 2016); however, the effects of fatty acids and BHB lipotoxicity on the GH-IGF-I axis of calf hepatocytes were not characterized. Therefore, the aim of the current study was to investigate (1) changes in the hepatic GH-IGF-I axis in ketotic cows and (2) the effects of fatty acids and BHB on the GH-IGF-I axis in calf hepatocytes, as well as the mechanisms underlying these effects.

\section{MATERIALS AND METHODS}

\section{Animals}

The Ethics Committee on the Use and Care of Animals of Jilin University approved the study protocol (Changchun, China; 2015 clinical trial [2015-121]). To ensure that the cows used in this study had no comorbidities, all cows received a routine physical examination. A TMR that met the animals' nutritional requirements was fed ad libitum once per day at 1100 $\mathrm{h}$; the basal diet formulation is shown in Table 1. We chose lactating Holstein cows with similar numbers of lactations (median $=3$, range $=2$ to 4 ) and DIM (median $=6 \mathrm{~d}$; range $=3$ to $9 \mathrm{~d}$ ) from a 1,000 -cow dairy farm located in Changchun, Jilin Province, China. The cows were classified as suspected clinical ketosis by veterinarians if feed intake, milk yield, or both were reduced and a nitroprusside test for ketone bodies in milk was positive (Duffield et al., 2009; Piechotta et al., 2012); subsequently, the blood concentration of BHB in these cows was measured. According to the clinical symptoms and serum BHB concentration (Oetzel, 2004), 15 clinically ketotic cows whose serum BHB concentration were higher than $3 \mathrm{mM}$ and 15 healthy cows whose serum BHB concentration were less than $0.6 \mathrm{mM}$ were chosen for the experiments. Characteristics of the ketotic and healthy cows are presented in Table 2.

The milk yield was recorded on 3 consecutive days at 0530 and $1500 \mathrm{~h}$. Blood samples were withdrawn from the jugular vein between 0800 and $0900 \mathrm{~h}$ and centrifuged at $3,500 \times g$ for $15 \mathrm{~min}$ at $4^{\circ} \mathrm{C}$. Blood was

Table 2. The basic description of healthy and ketotic cow (data were analyzed using non-parametric tests)

\begin{tabular}{|c|c|c|c|c|c|}
\hline \multirow[b]{2}{*}{ Item } & \multicolumn{2}{|c|}{ Ketosis $(\mathrm{n}=15)$} & \multicolumn{2}{|c|}{ Control $(\mathrm{n}=15)$} & \multirow[b]{2}{*}{$P$-value } \\
\hline & Median & Interquartile range & Median & Interquartile range & \\
\hline Milk production ( $\mathrm{kg}$ of milk/cow per day) & 25.6 & $24.3,26.4$ & 30 & $29.3,31.2$ & $<0.0001$ \\
\hline DMI $(\mathrm{kg} / \mathrm{d})$ & 20.1 & $19,20.5$ & 21.8 & $20.2,22.6$ & 0.0020 \\
\hline BCS & 3.16 & $3.05,3.2$ & 2.71 & $2.54,2.74$ & $<0.0001$ \\
\hline Glucose $(\mathrm{m} M)$ & 2.17 & $2.05,2.34$ & 4.13 & $4.01,4.27$ & $<0.0001$ \\
\hline
\end{tabular}


collected from all of the cows in the study at the same time. The serum was obtained and stored at $-80^{\circ} \mathrm{C}$ until analysis. Liver tissue samples were taken from the 11th or 12th right intercostal space by liver puncture needle (Shanghai Surgical Equipment Factory, Shanghai, China) after blood collection (Radcliff et al., 2003). Prior to liver biopsy, the intercostal space was shaved, sanitized with iodine scrub and $75 \%$ alcohol, and anesthetized by subcutaneous injection of $2 \%$ lidocaine $\mathrm{HCl}$ (Sigma-Aldrich Co., St. Louis, MO). A scalpel blade was used to make a $3-\mathrm{mm}$ stab incision in the skin. The puncture needle was then inserted through the intercostal muscle and into the liver. The liver tissue biopsies (approximately $150 \mathrm{mg}$ ) were immediately frozen in liquid nitrogen. During the experimental work, the cows were housed in a climate-controlled barn in individual tiestalls.

\section{Determination of Blood Parameters}

The concentration of BHB in the blood was measured using a Medisense Optium (Abbott Diabetes Care Inc., Alameda, CA; farm assay) with BHB test strips (Abbott Diabetes Care Inc.). The serum concentrations of glucose, BHB, and fatty acids were determined using a Hitachi 7170 autoanalyzer (Hitachi, Tokyo, Japan) and a commercially available kit [glucose: Cat. No. GL3815; BHB: Cat. No. RB1008; fatty acids: Cat. No. FA115 (Randox Laboratories, Crumlin, UK)] according to the manufacturer's instructions (Silva et al., 2017). The concentrations of GH and IGF-I in serum and medium were determined by RIA (Hammon and Blum, 1997; Egli and Blum, 1998). The antibody against bovine GH was purchased from Abcam (Cambridge, UK; ab31496). The intra- and interassay coefficients of variation for the GH and IGF-I assays were less than $5 \%$.

\section{Hepatocyte Isolation and Culture}

Calf hepatocytes were isolated using a modified 2-step collagenase perfusion method as previously described (Liu et al., 2014; Du et al., 2017a,b). Five calves (1 d old, female, 30-40 kg, healthy, and fasting) were used for hepatocyte isolation in this experiment. Hepatocytes were isolated from each calf separately and used in independent experiments. The caudate liver lobes of Holstein calves were obtained through surgical liver excision according to the method used in a previous study (Parker and Gaughan, 1988). Blood was removed from the surface of the caudate lobe by rinsing with perfusion solution A $(140 \mathrm{~m} M \mathrm{NaCl}, 10 \mathrm{~m} M$ HEPES, $6.7 \mathrm{~m} M \mathrm{KCl}, 0.5 \mathrm{~m} M$ EDTA, and $2.5 \mathrm{~m} M$ glucose, $\mathrm{pH}$ 7.2-7.4). A blood vessel of moderate size was intubated, and the liver was perfused with perfusion solution A $\left(37^{\circ} \mathrm{C}\right)$ at a flow rate of $50 \mathrm{~mL} / \mathrm{min}$ for $12 \mathrm{~min}$. The liver was then perfused with solution B $(140 \mathrm{mM} \mathrm{NaCl}$, $30 \mathrm{~m} M$ HEPES, $6.7 \mathrm{~m} M \mathrm{KCl}, 5 \mathrm{~m} M \mathrm{CaCl}_{2}$, and 2.5 $\mathrm{m} M$ glucose, $\mathrm{pH} 7.2-7.4$ ) at a flow rate of $50 \mathrm{~mL} / \mathrm{min}$ for $3 \mathrm{~min}$ until the perfusate was clear. Subsequently, the liver was perfused with a collagenase IV solution (0.1 g of collagenase IV dissolved in $0.5 \mathrm{~L}$ of perfusion solution $\mathrm{B}, \mathrm{pH} 7.2-7.4$ ) at a flow rate of $20 \mathrm{~mL} / \mathrm{min}$ for 15 to $20 \mathrm{~min}$. The liver was then placed on a sterile flat plate and $100 \mathrm{~mL}$ of fetal bovine serum was added to terminate the collagenase digestion. The liver was cut open and the liver capsule, blood vessels, fat, and connective tissue were removed using forceps and scissors. The liver parenchyma was filtered sequentially through $100-(150-\mu \mathrm{m})$ and $200-$ mesh $(75-\mu \mathrm{m})$ cell sieves. The hepatocyte suspension was washed twice in RPMI-1640 basic medium (Hyclone Laboratories, Logan, UT) and centrifuged for $5 \mathrm{~min}$ at $500 \times \mathrm{g}$ at $4^{\circ} \mathrm{C}$. The hepatocyte suspension was seeded into a 6 -well tissue culture plate $(2 \mathrm{~mL} /$ well $)$ at $1 \times 10^{6}$ cells $/ \mathrm{mL}$ using adherent medium (RPMI-1640 basic medium supplemented with $10 \%$ fetal bovine serum, $10^{-6} \mathrm{~mol} / \mathrm{L}$ of insulin, $10^{-6}$ $\mathrm{mol} / \mathrm{L}$ of dexamethasone, and $10 \mu \mathrm{g} / \mathrm{mL}$ of vitamin $\mathrm{C})$. The hepatocytes were incubated at $37^{\circ} \mathrm{C}$ in $5 \% \mathrm{CO}_{2}$. After $4 \mathrm{~h}$, the medium was replaced with growth medium containing $10 \%$ fetal bovine serum. The growth medium was replaced every $24 \mathrm{~h}$.

\section{Hepatocyte Treatments}

Prior to treatment, the hepatocytes were cultured for $6 \mathrm{~h}$ without serum. Hepatocytes were maintained in RPMI-1640 basic medium and treated with 0, 5, 10 or $20 \mathrm{ng} / \mathrm{mL}$ GH (ProSpec, East Brunswick, NJ) for $3 \mathrm{~h}$. The concentrations of fatty acids and BHB used in the treatments in our study were based on the concentrations of fatty acids and BHB in the blood of clinically ketotic cows (Rukkwamsuk et al., 2000; Oetzel, 2004). The fatty acid components (oleic acid, linoleic acid, palmitic acid, stearic acid, and palmitoleic acid; SigmaAldrich) used in this study were chosen based on the fatty acids found in the blood of ketotic cows (Yamdagni and Schultz, 1970). The fatty acids were diluted in $0.1 \mathrm{M} \mathrm{KOH}$ at $60^{\circ} \mathrm{C}$ and the $\mathrm{pH}$ of the fatty acid solution was adjusted to 7.4 with hydrochloric acid (1 $M)$. The stock fatty acid $(52.7 \mathrm{mM})$ solution included oleic acid $(22.9 \mathrm{~m} M)$, linoleic acid $(2.6 \mathrm{mM})$, palmitic acid $(16.8 \mathrm{mM})$, stearic acid $(7.6 \mathrm{mM})$, and palmitoleic acid $(2.8 \mathrm{mM})$. When hepatocytes were co-treated with GH and fatty acids, hepatocytes were treated with 10 $\mathrm{ng} / \mathrm{mL}$ of $\mathrm{GH}$ for $3 \mathrm{~h}$ and the medium was renewed, and then hepatocytes were maintained in RPMI-1640 basic 
medium containing $2 \%$ BSA and treated with $0,0.6$, 1.2 , or $2.4 \mathrm{~m} M$ fatty acids for $12 \mathrm{~h}$. The BHB was used in its sodium salt form as sodium $\beta$-hydroxybutyrate (Sigma-Aldrich); BHB powder was dissolved in distilled water and sterilized by filtration. When hepatocytes were co-treated with $\mathrm{GH}$ and $\mathrm{BHB}$, hepatocytes were treated with $10 \mathrm{ng} / \mathrm{mL}$ of $\mathrm{GH}$ for $3 \mathrm{~h}$ and the medium was renewed, and then hepatocytes were maintained in RPMI-1640 basic medium and treated with $0,1.2$, 2.4 , or $4.8 \mathrm{~m} M$ BHB for $12 \mathrm{~h}$. The cell treatments and detailed groupings are described in the figure legends.

\section{Quantitative Real-Time PCR Assay}

The total RNA of hepatocytes and liver tissues was extracted using RNAiso Plus (TaKaRa Biotechnology Co. Ltd., Dalian, China) according to the manufacturer's instructions (http://www.takarabiomed.com.cn/ DownLoad/9108-9109.pdf). The RNA concentration and quality were measured using a K5500 MicroSpectrophotometer (Beijing Kaiao Technology Development Ltd., Beijing, China) and by electrophoresis (1\% agarose gels). One microgram of the total RNA in each sample was then reverse-transcribed to cDNA in $20-\mu \mathrm{L}$ reactions using a reverse transcription kit (TaKaRa Biotechnology Co. Ltd.) according to the supplier's protocol (http://www.takarabiomed.com.cn/DownLoad/ RR036A.pdf). We evaluated mRNA expression levels using quantitative real-time (qRT)-PCR technology with the SYBR Green QuantiTect RT-PCR Kit (TaKaRa Biotechnology Co. Ltd.) and a 7500 Real-Time PCR System (Applied Biosystems Inc., Waltham, MA). The qRT-PCR was conducted with initial denaturation at $94^{\circ} \mathrm{C}$ for $2 \mathrm{~min}, 35$ cycles of amplification (denaturation at $94^{\circ} \mathrm{C}$ for $10 \mathrm{~s}$, annealing at $60^{\circ} \mathrm{C}$ for $15 \mathrm{~s}$, and extension at $72^{\circ} \mathrm{C}$ for $30 \mathrm{~s}$ ), and extension at $72^{\circ} \mathrm{C}$ for $5 \mathrm{~min}$. The PCR efficiency (E) and correlation coefficient were determined based on the slope of the standard curves generated using serial 10-fold dilutions of sample cDNA. The efficiency was calculated as $\mathrm{E}$ $(\%)=\left(10^{-1 / \text { slope }}-1\right) \times 100$ (Kubista et al., 2006). The relative expression of each target gene was normalized to $\beta$-actin and calculated by a mathematical model, which includes an efficiency correction for PCR efficiency (Pfaffl, 2001). The PCR reaction was performed in triplicate for each cow and 15 cows were included in per group; PCR reaction was performed 15 times in each group. The primers used for GHR, IGF-I, and $\beta$-actin are shown in Supplemental Table S1 (https:// doi.org/10.3168/jds.2017-13234); $\beta$-actin was stably expressed in different groups (Supplemental Figure S1, https://doi.org/10.3168/jds.2017-13234; Morey et al.,
2011; Li et al., 2012). The efficiency of used primers was added in the Supplemental Table S2 (https://doi .org/10.3168/jds.2017-13234).

\section{Western Blotting Assay}

Western blotting was performed as previously described (Dessauge et al., 2011). Briefly, the protein concentrations in extracts of hepatocytes and liver tissues were determined using a protein assay kit (Sangon Biotech Co. Ltd., Shanghai, China) after extraction of the hepatocytes and tissues according to the manufacturer's instructions (http://www.sangon.com/ productImage/DOC/C510003/C510003_ZH_P.pdf). A total of $30 \mu \mathrm{g}$ of protein from each sample was separated by $12 \%$ SDS-PAGE and electrophoretically transferred to a polyvinylidene difluoride membrane. The membranes were blocked in 3\% BSA/Tris-buffered saline/Tween (TBS-T) buffer for $4 \mathrm{~h}$. The blocked membranes were incubated overnight at $4^{\circ} \mathrm{C}$ with primary antibodies against GHR1A (1:200; Cat. sc-20748; Santa Cruz Biotechnologies, Santa Cruz, CA), JAK2 (1:1,000; Cat. 4040), phospho (p)-STAT5 (Tyr694; 1:1,000; Cat. 4322; Cell Signaling Technology, Danvers, MA), STAT5 (1:500; Cat. ab68465), and $\beta$-actin $(1: 2,000 ;$ Cat. ab8226; Abcam). The membranes were then washed with TBS-T and incubated with horseradish peroxidase-conjugated anti-rabbit or anti-mouse immunoglobulin at room temperature for $45 \mathrm{~min}$. Immunoreactive bands were visualized by enhanced chemiluminescence solution (ECL, Beyotime Biotechnology Inc., Shanghai, China). Finally, the bands were imaged using a ProteinSimple imager (ProteinSimple, Santa Clara, CA). The phosphorylation levels of STAT5 were calculated as p-STAT5/total STAT5.

\section{Immunofluorescence Assay}

An immunofluorescence assay was performed as previously described (Song et al., 2016). Hepatocytes were divided into 4 groups: control group, GH treatment group (hepatocytes were treated with $10 \mathrm{ng} / \mathrm{mL}$ of $\mathrm{GH}$ for $3 \mathrm{~h}$ ), $\mathrm{GH}+$ fatty acids group (hepatocytes were treated with $10 \mathrm{ng} / \mathrm{mL} \mathrm{GH}$ for $3 \mathrm{~h}$ and the medium was renewed, and then hepatocytes were treated with 1.2 $\mathrm{m} M$ fatty acids for $12 \mathrm{~h}$ ), and $\mathrm{GH}+\mathrm{BHBA}$ group (hepatocytes were treated with $10 \mathrm{ng} / \mathrm{mL}$ of $\mathrm{GH}$ for $3 \mathrm{~h}$ and the medium was renewed, and then hepatocytes were treated with $4.8 \mathrm{mM}$ BHB for $12 \mathrm{~h}$ ). The hepatocytes were fixed with $10 \%$ formalin in $0.1 \%$ PBS for $20 \mathrm{~min}$. Antigen retrieval was performed using EDTA-Na $\mathrm{Na}_{2}$ at $95^{\circ} \mathrm{C}$ for $5 \mathrm{~min}$. The hepatocytes were permeabilized us- 
ing $0.1 \%$ Triton X-100 (Sigma-Aldrich) and incubated with an antibody to p-STAT5 (diluted 1:100 with $0.1 \%$ PBS containing $5 \%$ goat serum) overnight at $4^{\circ} \mathrm{C}$. The hepatocytes were then incubated for $30 \mathrm{~min}$ at room temperature with secondary antibodies conjugated to Cy3 (Beyotime, Beyotime Institute of Biotechnology, Jiangsu, China). We stained the hepatocyte nuclei with Hoechst 33258 (Beyotime) for 20 min. The coverslips were then sealed with glycerol and the samples were imaged using laser confocal microscopy (Fluoview FV1200, Olympus, Japan). The immunofluorescence experiments were repeated 3 times; each time, at least 3 zones were selected for measurement. Image-Pro Plus software (Media Cybernetics, Rockville, MD) was used to quantify the immunofluorescent signals.

\section{Statistical Analysis}

In the in vivo studies, data on baseline characteristics and data from Western blots and qRT-PCR were analyzed using nonparametric tests and paired $t$ tests, respectively. In the in vitro studies, comparisons among groups were calculated using a 1-way ANOVA with subsequent Bonferroni correction. All analyses were performed using GraphPad Prism 5.0 (Graph Pad Software, San Diego, CA) or SPSS (Statistical Package for the Social Sciences) 19.0 software (IBM, Armonk, NY). Baseline characteristics are expressed as the median and interquartile range, and other data are expressed as the mean \pm SEM; $P<0.05$ was considered statistically significant.

\section{RESULTS}

\section{Ketotic Cows Displayed Uncoupled GH-Mediated JAK2-STAT5 Pathway}

As shown in Table 2, the milk production, DMI, and blood concentration of glucose were significantly lower in ketotic cows than in control cows. Conversely, the blood concentrations of fatty acids and BHB were significantly higher in ketotic cows than in control cows.

We found that the blood concentration of $\mathrm{GH}$ was significantly higher in clinically ketotic cows than in control cows (Figure 1A). Conversely, the blood concentration of IGF-I was significantly decreased in clinically ketotic cows compared with control cows (Figure 1B). To further investigate the hepatic GH-IGF-I axis, the GH-mediated JAK2-STAT5 signaling pathway in the livers of clinically ketotic and healthy cows was measured. The mRNA and protein expression of hepatic GHR1A were significantly lower in clinically ketotic cows than in control cows (Figure 1C, D and
E). The protein level of JAK2 and the phosphorylation level of STAT5 were also significantly decreased in the livers of clinically ketotic cows (Figure 1D, F and G); consequently, the hepatic IGF1 mRNA level was lower in clinically ketotic cows than in control cows (Figure $1 \mathrm{H})$. Taken together, these results indicate that the GH-mediated JAK2-STAT5 signaling pathway is less sensitive in ketotic compared with healthy cows.

\section{GH Activated JAK2-STAT5 Signaling Pathway and Increased Production of IGF-I}

Calf hepatocytes were treated with $\mathrm{GH}$ at $0,5,10$, or $20 \mathrm{ng} / \mathrm{mL}$. The cell viability was not decreased by GH treatment (Supplemental Figure S2; https://doi.org/10 $.3168 /$ jds.2017-13234). Following treatment with GH, the GHR1A mRNA level increased gradually in a $\mathrm{GH}$ dose-dependent manner; it was significantly higher in the 10 and $20 \mathrm{ng} / \mathrm{mL} \mathrm{GH}$ treatment groups than in the control group (Figure 2A). Treatment with GH also significantly increased the JAK2 protein level and the STAT5 phosphorylation level in the hepatocytes (Figure $2 \mathrm{~B}, \mathrm{C}$ and $\mathrm{D})$. More importantly, the IGF1 mRNA level in the hepatocytes and the content of IGF-I in the medium also increased gradually, and both were markedly higher in the 10 and $20 \mathrm{ng} / \mathrm{mL}$ GH treatment groups than in the control group (Figure $2 \mathrm{E}$ and F). Together, these data suggest that GH activated the JAK2-STAT5 signaling pathway and subsequently increased the production of IGF-I in calf hepatocytes.

\section{High Concentrations of Fatty Acids Inhibited GH-IGF-I Axis in Calf Hepatocytes}

To investigate the effect of high concentrations of fatty acids on the GH-IGF-I axis, calf hepatocytes were treated with GH and fatty acids. We also performed the control experiments using different volumes of fatty acid solvent $(0.01 \mathrm{M} \mathrm{KCl} ; 0,22.78,45.54$, and 91.08 $\mu \mathrm{L}$ ), and the results showed that different solvent volumes had no effects on cell viability or mRNA expression of GHR1A and IGF1 (Supplemental Figure S3; https://doi.org/10.3168/jds.2017-13234). The GHR1A mRNA level was significantly decreased in the fatty acid and GH co-treatment groups compared with the GH treatment group (Figure 3A). Similarly, the levels of JAK2 protein expression and STAT5 phosphorylation were markedly decreased in the fatty acid and $\mathrm{GH}$ co-treatment groups (Figure 3B, C and D). To confirm the effect of fatty acids on the GH-mediated JAK2STAT5 pathway in calf hepatocytes, the expression and nuclear translocation of p-STAT5 were determined using an immunofluorescence assay. Treatment with GH 
significantly increased the fluorescence intensity and the nuclear translocation of p-STAT5 in calf hepatocytes (Figure $3 \mathrm{G}$ and $\mathrm{H}$ ). Importantly, fatty acid treatment significantly decreased the fluorescence intensity and the nuclear translocation of p-STAT5 (Figure 3G and $\mathrm{H}$ ). More importantly, fatty acids also significantly decreased the IGF1 mRNA level in the hepatocytes and the content of IGF-I in the medium (Figure 3E and F). Taken together, these results show that high concentration of fatty acids significantly inhibit the GH-mediated JAK2-STAT5 signaling pathway and further downregulate the expression of IGF-I.

\section{High Concentrations of BHB Inhibited the GH-IGF-I Axis in Calf Hepatocytes}

Calf hepatocytes were treated with $\mathrm{GH}$ and BHB. The level of GHR1A mRNA was significantly decreased in the $\mathrm{BHB}$ and $\mathrm{GH}$ co-treatment groups compared with the GH treatment group (Figure 4A). The JAK2 protein level and the STAT5 phosphorylation level were also markedly decreased in the BHB and GH cotreatment groups (Figure 4B, C and D). Importantly, BHB treatment significantly decreased the fluorescence intensity and the nuclear translocation of p-STAT5
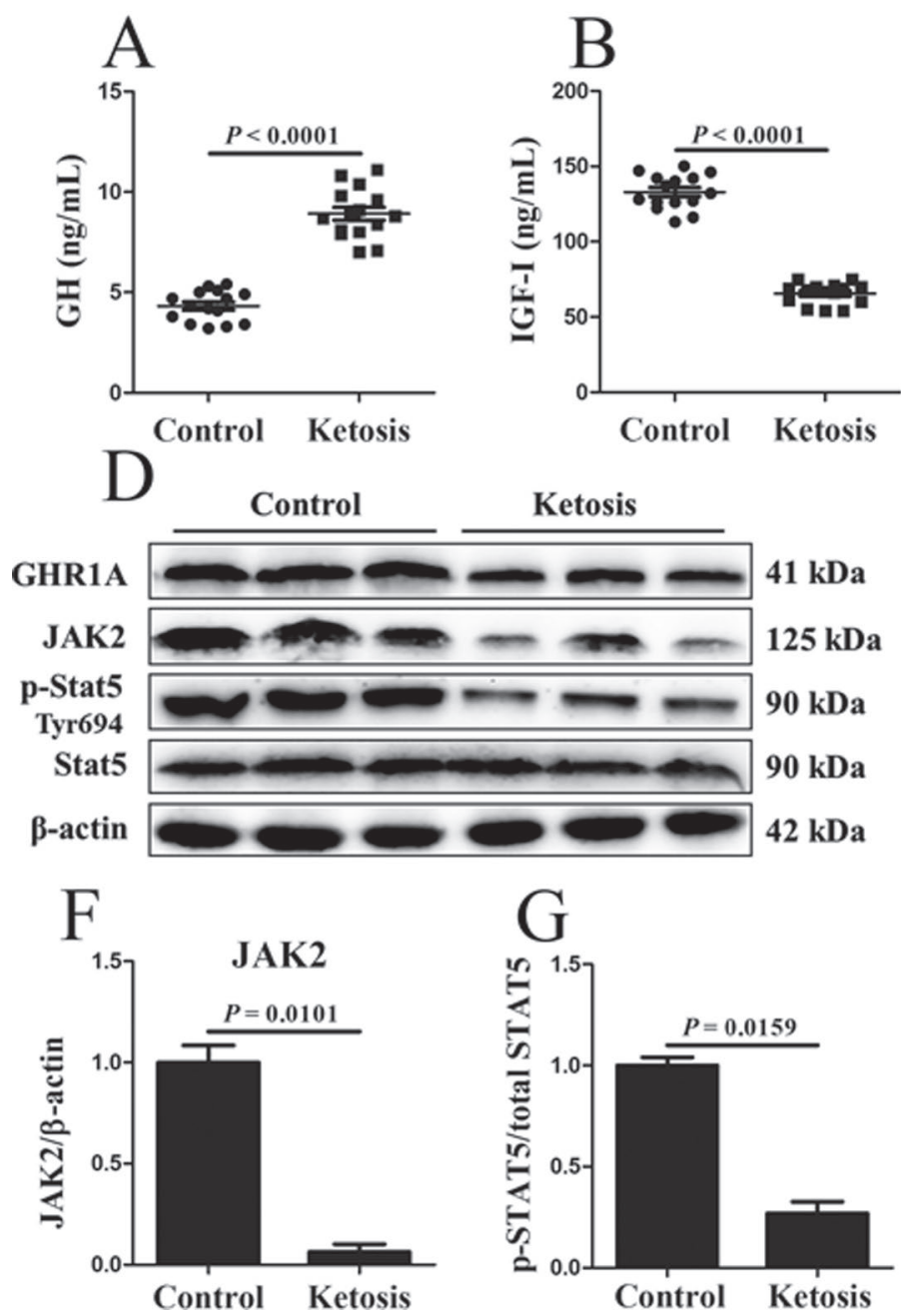
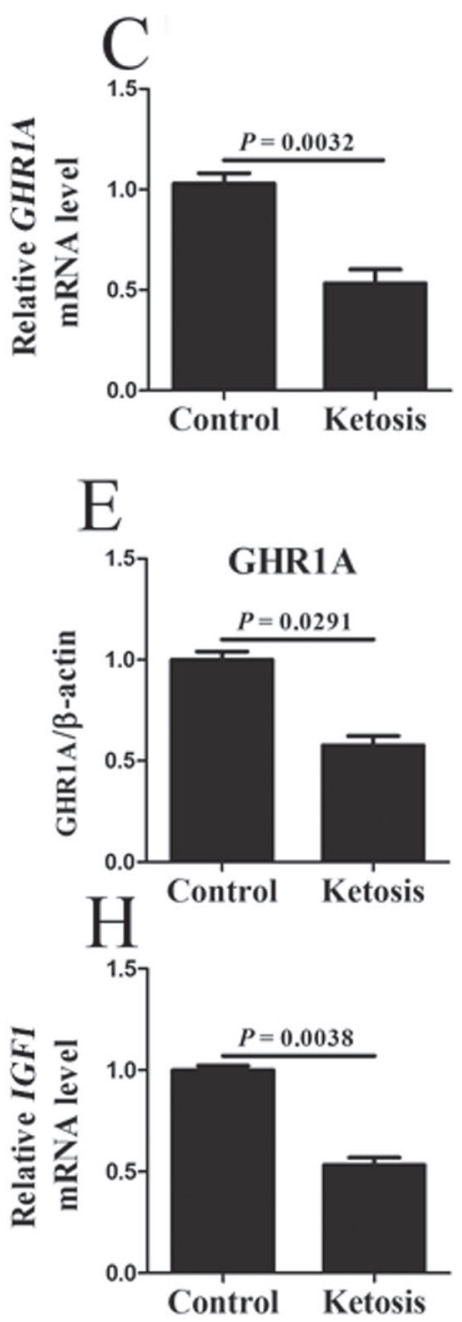

Figure 1. Changes in the growth hormone (GH)-IGF-I axis and the hepatic activating janus kinase 2 (JAK2)-signal transducer and activator of transcription 5 (STAT5) signaling pathway in ketotic and healthy cows. (A) Blood concentration of GH in ketotic $(\mathrm{n}=15)$ and healthy $(\mathrm{n}=$ $15)$ cows. (B) Blood concentration of IGF-I in ketotic $(\mathrm{n}=15)$ and healthy $(\mathrm{n}=15)$ cows. $(\mathrm{C})$ Relative growth hormone receptor $1 \mathrm{~A}(G H R 1 A)$ mRNA levels in ketotic $(\mathrm{n}=15)$ and healthy $(\mathrm{n}=15)$ cows. $(\mathrm{D})$ Hepatic protein levels of GHR1A, JAK2, phospho (p)-STAT5, STAT5, and $\beta$-actin in ketotic $(\mathrm{n}=15)$ and healthy $(\mathrm{n}=15)$ cows. Representative blots are shown. $(\mathrm{E}, \mathrm{F}, \mathrm{G})$ Quantification of hepatic protein levels of GHR1A, JAK2, and p-STAT5. (H) Relative IGF1 mRNA levels in ketotic $(\mathrm{n}=15)$ and healthy $(\mathrm{n}=15)$ cows. The mRNA expression levels of the ketosis group were normalized to control group. Panels A and B were analyzed using nonparametric tests; panels C, E, F, G, and H were analyzed using paired $t$ tests. The data are presented as mean \pm SEM. 

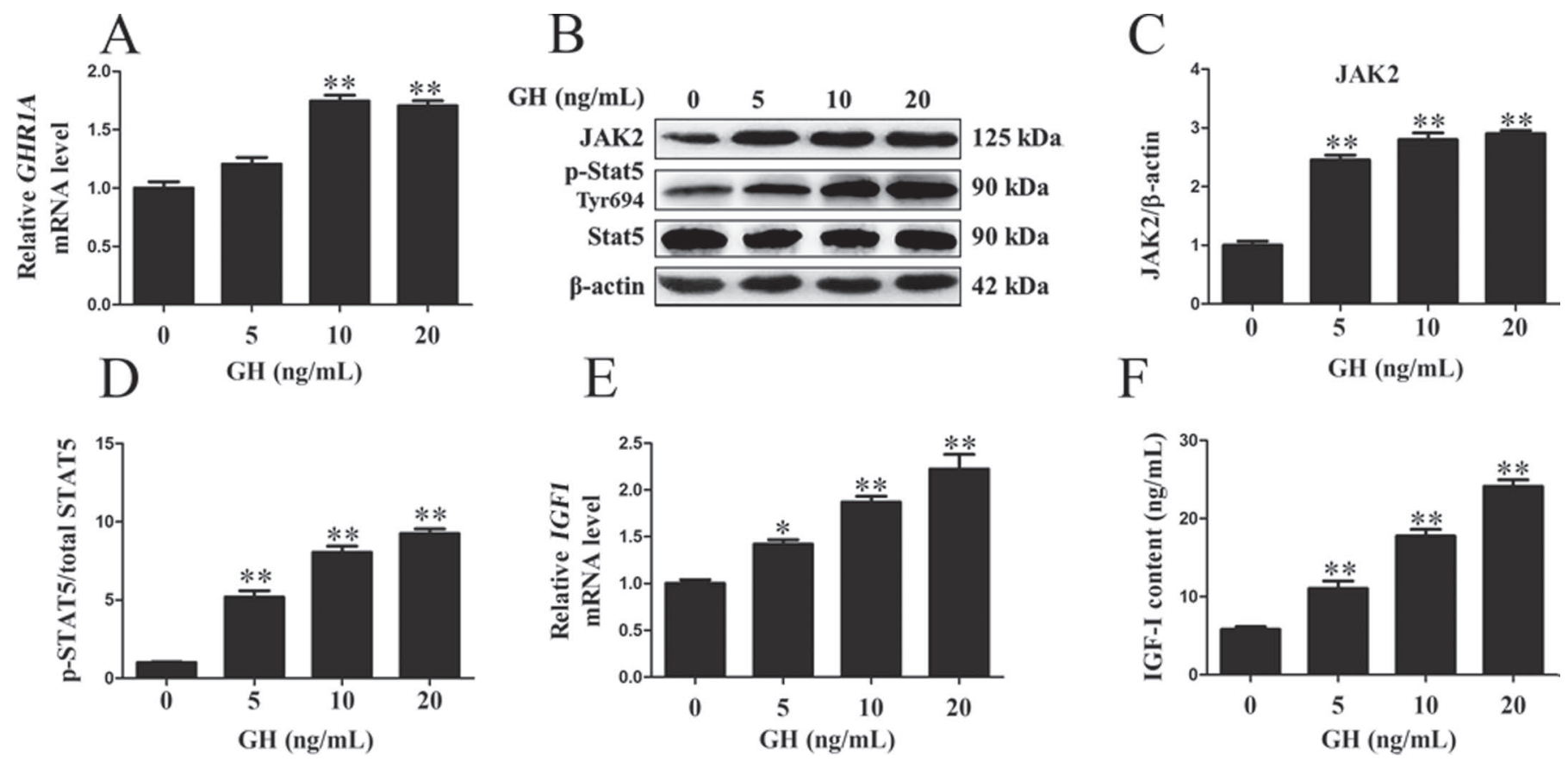

Figure 2. Effects of growth hormone $(\mathrm{GH})$ on the activating janus kinase 2 (JAK2)-signal transducer and activator of transcription 5 (STAT5) signaling pathway in calf hepatocytes. Calf hepatocytes were treated with various concentrations of $\mathrm{GH}(0,5,10, \mathrm{and} 20 \mathrm{ng} / \mathrm{mL})$. (A) Relative levels of growth hormone receptor 1A (GHR1A) mRNA in calf hepatocytes. (B) Protein levels of JAK2, phospho (p)-STAT5, STAT5, and $\beta$-actin in calf hepatocytes. (C and D) Quantification of protein levels of JAK2 and p-STAT5. (E) Relative levels of IGF1 mRNA in calf hepatocytes. (F) IGF-I content of the medium. The mRNA expression levels of the hepatocyte treatment groups were normalized to control group. Data were analyzed using a 1 -way ANOVA with subsequent Bonferroni correction. The data are presented as mean \pm SEM. ${ }^{*} P<0.05$; $* * P<0.01$.

(Figure $3 \mathrm{G}$ and $\mathrm{H}$ ). In addition, the IGF1 mRNA level and the IGF-I content of the medium was significantly lower in hepatocytes co-treated with GH and BHB than in hepatocytes treated with GH alone (Figure 4E and $\mathrm{F}$ ). These results indicate that high concentrations of BHB also significantly inhibited the GH-mediated JAK2-STAT5 pathway and further downregulated the expression of IGF-I.

\section{DISCUSSION}

The change in nutrient metabolism required to support lactation in high-producing dairy cows is controlled by hormones that coordinate a variety of processes, including the mobilization of fatty acids from adipose tissue and the synthesis of glucose in the liver (Radcliff et al., 2003). Therefore, dramatic endocrine changes occur during the transition period in dairy cows to regulate the required metabolic changes (Gross et al., 2011). Previous studies have shown that blood GH concentration increases shortly after parturition and that this increase coincides with a precipitous decline in blood IGF-I concentration (Hammon and Blum, 1997; Kobayashi et al., 1999; Radcliff et al., 2006; Piechotta et al., 2012). The increase in blood GH promotes lipolysis in adipose tissue (Radcliff et al., 2003). Results obtained in mice showed that impairment of the GH-IGF-I axis was the response for liver steatosis and that inhibition of endogenous GH signaling could induce disorders in hepatic lipid metabolism (Fan et al., 2014). Interestingly, Radcliff et al. (2006) reported that postpartum dairy cows with NEB induced by feed restriction on the first day of lactation displayed high blood concentrations of GH and low blood concentrations of IGF-I (Radcliff et al., 2006). We also found that the blood concentration of GH was significantly higher and the blood concentration of IGF-I was significantly lower in clinically ketotic cows than in control cows. A decrease in blood IGF-I level reduces negative feedback for GH synthesis and secretion (Romero et al., 2012), and the loss of negative feedback results in an increase in blood GH concentration (Lundberg et al., 2015). The increase in blood GH promotes lipolysis in adipose tissue and further increases blood fatty acid concentration (Corbit et al., 2017). Moreover, a high blood concentration of fatty acids is a pathological factor of ketosis; fatty acids absorbed by the liver from plasma are metabolized into ketone bodies (BHB, acetoacetate, and acetone) in 
hepatocytes. Therefore, uncoupling of the somatotropic axis may be a cause of ketosis.

The actions of GH are mediated via the GHR, and at least 3 alternative forms of $G H R$ mRNA exist in cattle (GHR1A, 1B, and 1C; Radcliff et al., 2003). The liverspecific GHR1A mRNA is believed to give rise to the bulk of functionally active GHR in the liver (Radcliff et al., 2003). One study reported that GHR1A mRNA expression decreased significantly between $\mathrm{d} 0$ and 1 and then decreased further from d 1 to 2 after isolation of adult primary bovine hepatocytes (Ehrhardt and Schmicke, 2016). Our results showed that GHR1A
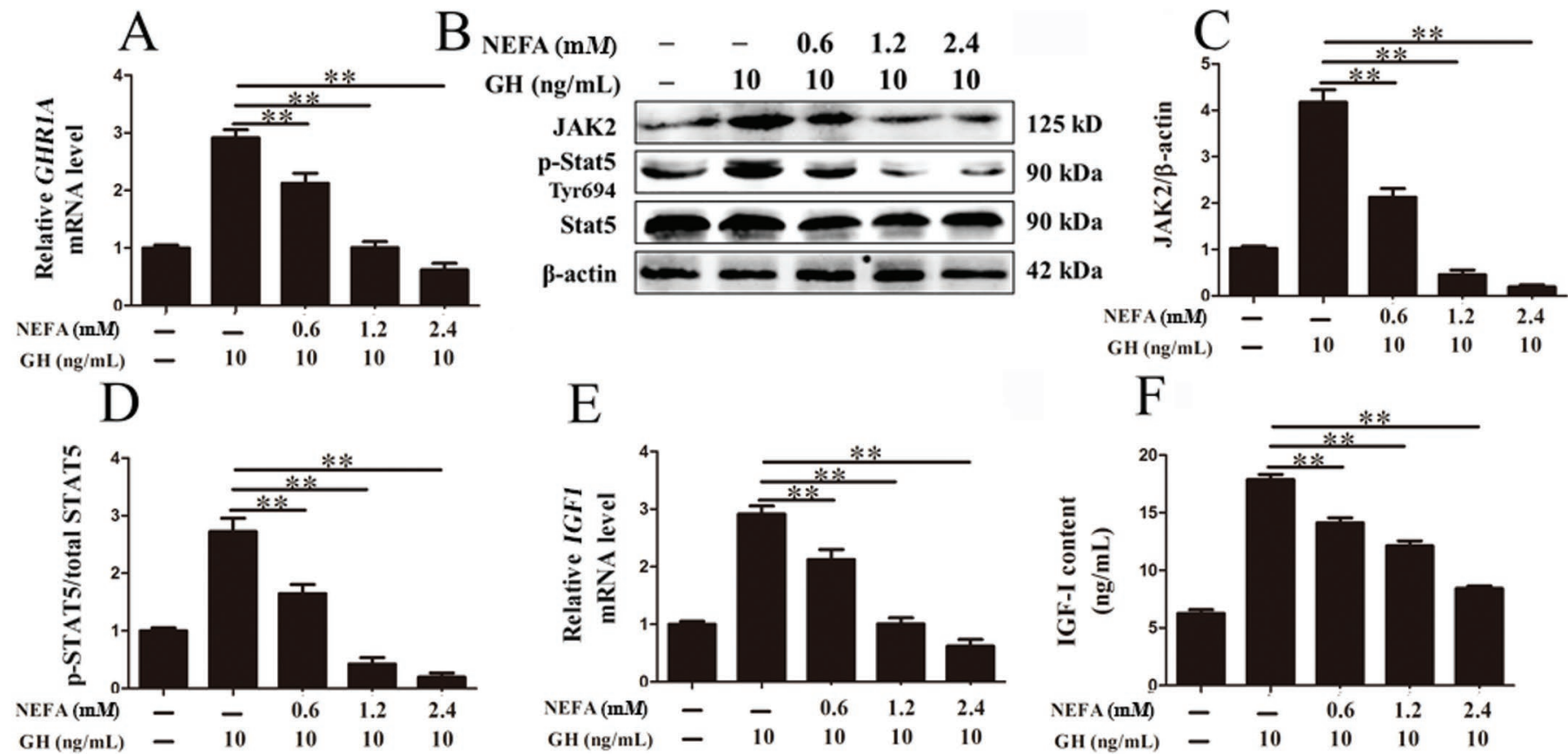

$\mathrm{E}$
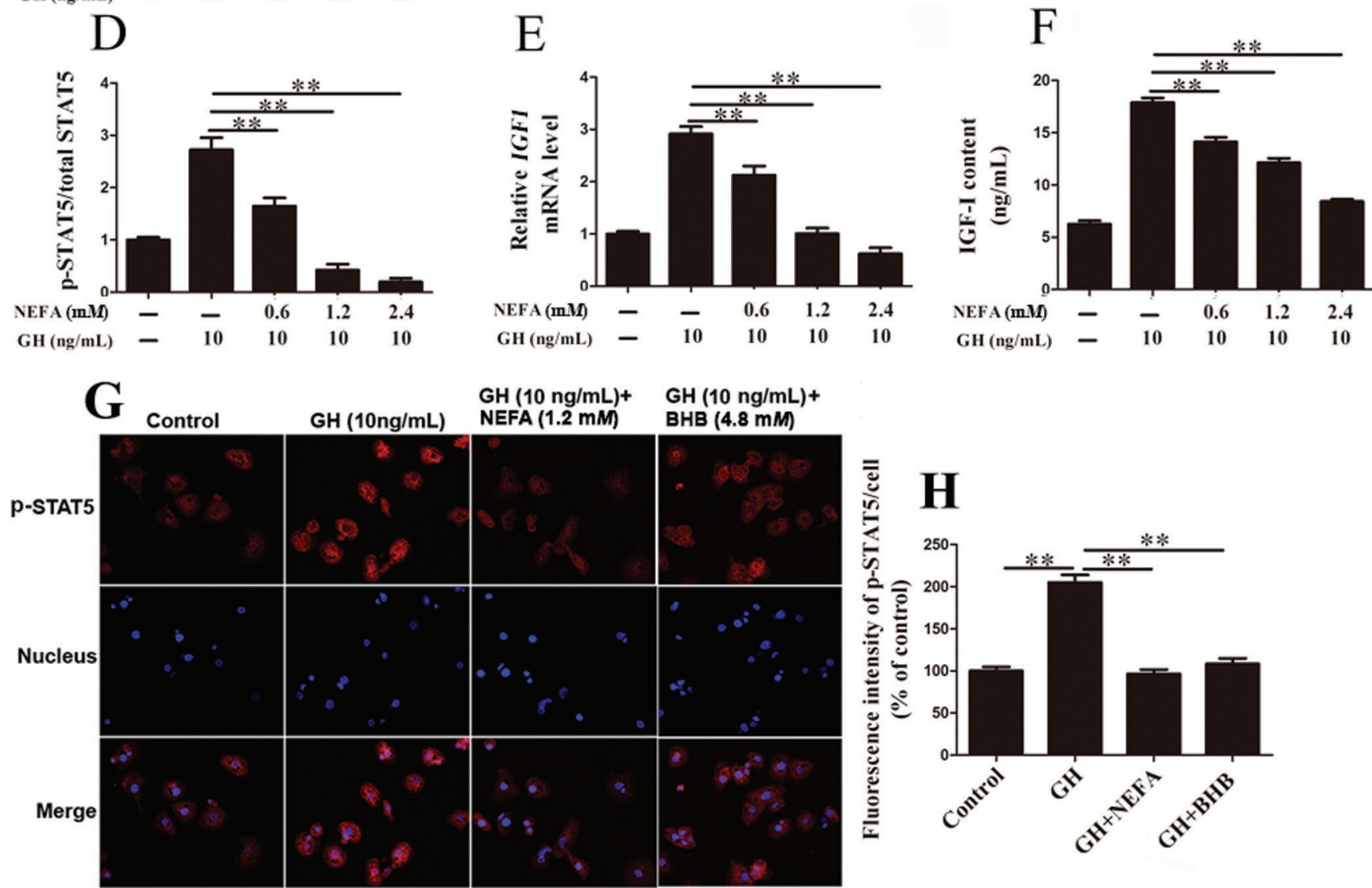

Figure 3. Effects of fatty acids on the activating janus kinase 2 (JAK2)-signal transducer and activator of transcription 5 (STAT5) signaling pathway and on IGF-I production in calf hepatocytes. Hepatocytes were treated with $10 \mathrm{ng} / \mathrm{mL}$ of growth hormone (GH) for $3 \mathrm{~h}$ and the medium was renewed, and then hepatocytes were maintained in RPMI-1640 (Hyclone Laboratories, Logan, UT) basic medium containing 2\% BSA and treated with $0,0.6,1.2$, or $2.4 \mathrm{~m} M$ for $12 \mathrm{~h}$. (A) Relative levels of growth hormone receptor $1 \mathrm{~A}(G H R 1 A)$ mRNA in calf hepatocytes. (B) Protein levels of JAK2, phospho (p)-STAT5, STAT5, and $\beta$-actin in calf hepatocytes. (C and D) Quantification of protein levels of JAK2 and p-STAT5. (E) Relative levels of IGF1 mRNA in calf hepatocytes. (F) IGF-I content of the medium. (G and H) Fluorescence intensity and nuclear translocation of p-STAT5 in calf hepatocytes. The mRNA expression levels of the hepatocyte treatment groups were normalized to control group. Data were analyzed using a 1-way ANOVA with subsequent Bonferroni correction. The data are presented as mean \pm SEM. $* * P$ $<0.01$. Color version available online. 

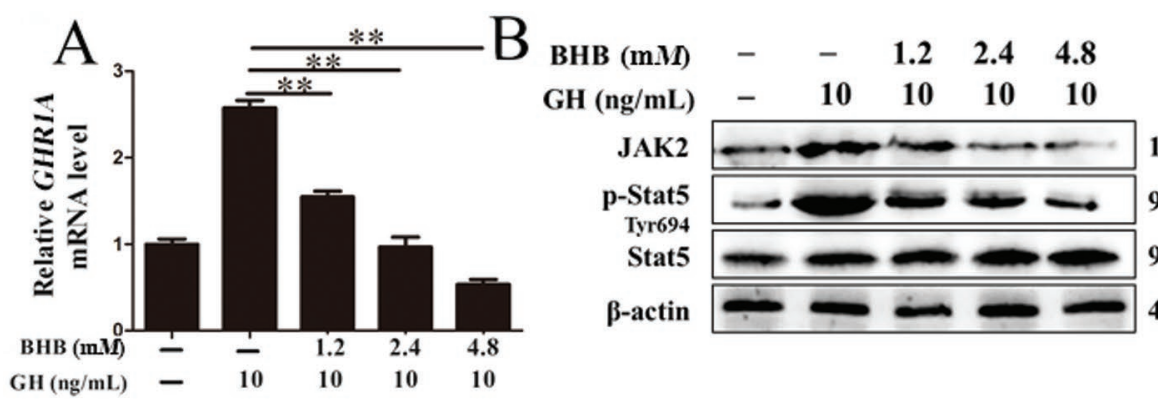

$125 \mathrm{kDa}$

$90 \mathrm{kDa}$

$90 \mathrm{kDa}$

$\mathrm{GH}(\mathrm{ng} / \mathrm{mL}) \quad-\quad 10 \quad 10 \quad 10 \quad 10$
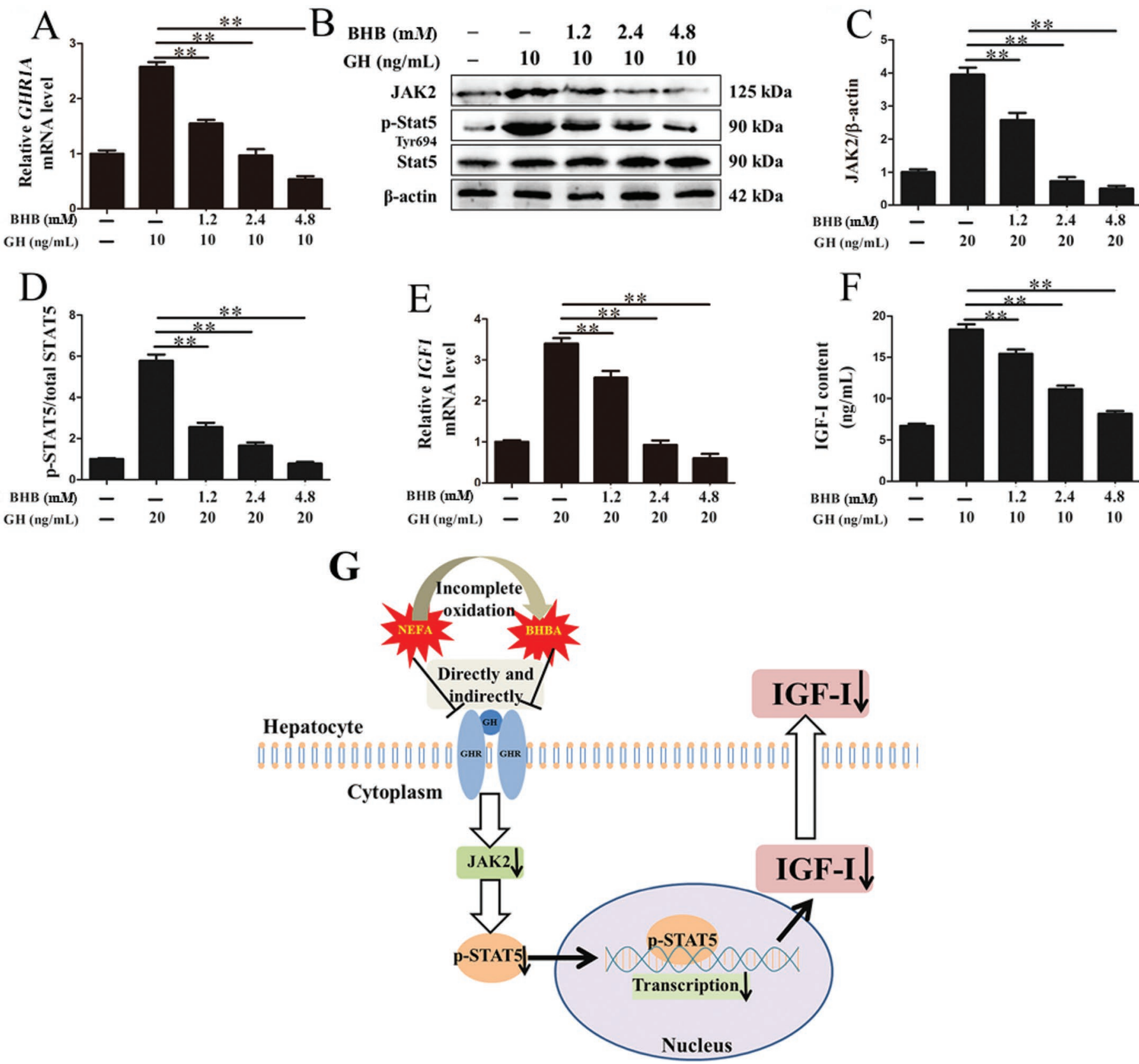

Figure 4. Effects of BHB on the activating janus kinase 2 (JAK2)-signal transducer and activator of transcription 5 (STAT5) signaling pathway and on IGF-I production in calf hepatocytes. Hepatocytes were treated with $10 \mathrm{ng} / \mathrm{mL}$ of growth hormone (GH) for $3 \mathrm{~h}$ and the medium was renewed, and then hepatocytes were maintained in RPMI-1640 (Hyclone Laboratories, Logan, UT) basic medium and treated with 0, 1.2, 2.4, or $4.8 \mathrm{mM}$ BHB for $12 \mathrm{~h}$. (A) Relative levels of growth hormone receptor 1A (GHR1A) mRNA in calf hepatocytes. (B) Protein levels of JAK2, phospho (p)-STAT5, STAT5, and $\beta$-actin in calf hepatocytes. (C and D) Quantification of protein levels of JAK2 and p-STAT5. (E) Relative levels of IGFI mRNA in calf hepatocytes. (F) IGF-I content of the medium. The mRNA expression levels of the hepatocyte treatment groups were normalized to control group. (G) Proposed model of the GH-IGF-I axis and the JAK2-STAT5 signaling pathway in calf hepatocytes. Excess fatty acids and BHB in the liver decrease GHR1A expression, which in turn decrease JAK2 expression and the expression and nuclear translocation of p-STAT5, resulting in reduced IGF-I synthesis and secretion. Data were analyzed using a 1-way ANOVA with subsequent Bonferroni correction. The data are presented as mean \pm SEM. ${ }^{* *} P<0.01$. Color version available online.

mRNA expression in calf hepatocytes decreased significantly between $\mathrm{d} 0$ and 1 and then remained constant from d 1 through 3 (Supplemental Figure S4; https:// doi.org/10.3168/jds.2017-13234). The discrepancies between the results obtained in our study and previous studies may have been caused by differences between 
calf hepatocytes and adult bovine hepatocytes. Besides, several differences exist between cow and calf hepatocytes, including cell viability, cell function, and hormone sensitivity. Therefore, to investigate the effects of GH on adult primary bovine hepatocytes, additional studies will be necessary.

Growth hormone binds GHR, resulting in activation of JAK2 and phosphorylation of STAT5. Phosphorylated STAT5 translocates to the nucleus, where it activates transcription of the IGF1 gene (Hanson et al., 2017). Our experiments also showed that calf hepatocytes treated with GH exhibited a significant increase in GHR1A mRNA expression, JAK2-STAT5 pathway activation, and IGF-1 secretion. Furthermore, Silva et al. (2017) also demonstrated that treatment of postpartum cows with $125 \mathrm{mg}$ of recombinant bST upregulated hepatic GHR1A mRNA expression and increased IGFI concentration by approximately $30 \%$ (Silva et al., 2017). Therefore, our data and the data reported in the previous study both suggest that GH regulates IGF-I expression and secretion. However, the GH-mediated JAK2-STAT5 signaling pathway in the liver tissue of ketotic cows has not been investigated. In our study, hepatic GHR1A mRNA and protein expression as well as the IGF-I concentration in blood were significantly decreased in clinically ketotic cows. More importantly, the hepatic JAK2 protein level and the STAT5 phosphorylation level were also markedly decreased. These data indicate that the hepatic GH-IGF-I axis was uncoupled and that the JAK2-STAT5 signaling pathway was impaired in clinically ketotic cows.

Dairy cows with ketosis are characterized by high blood concentrations of fatty acids and BHB. Our previous studies demonstrated that high levels of fatty acids and BHB induce hepatic oxidative stress, apoptosis, and inflammation (Shi et al., 2014; Song et al., 2014, 2016; Deng et al., 2015). Therefore, we speculated that high blood concentrations of fatty acids and BHB might impair the GH-induced JAK2-STAT5 pathway and further affect the expression and synthesis of IGF-I in hepatocytes. To address this question, calf hepatocytes were cultured and treated with $\mathrm{GH}$, fatty acids, or BHB. Our results showed that treatment of hepatocytes with high concentrations of fatty acids or BHB markedly downregulated GHR1A expression, JAK2 protein level, and STAT5 phosphorylation. Importantly, we found that treatment with fatty acids or BHB significantly inhibited the nuclear translocation of p-STAT5. The decreased expression and nuclear translocation of p-STAT5 caused reduced expression of IGF-I in calf hepatocytes. The inhibitory effects of fatty acids and BHB on hepatic IGF-I expression are consistent with the low blood concentration of IGF-I in ketotic cows.
In a previous study, it was reported that SFA (palmitic acid and myristic acid) inhibit the activity of the $G H R$ gene promoter and that this effect is mediated by direct action of the fatty acids (Thimmarayappa et al., 2006). Palmitic acid is an important component of fatty acids and the specific mechanism of BHB-reduced GHR1A expression has never been reported. Taken together, our results and those of previous studies indicate that high concentrations of fatty acids and BHB inhibit GHR1A expression and JAK2-STAT5 pathway both directly and indirectly in the hepatocytes of ketotic cows and subsequently decrease the expression and secretion of IGF-I. The results also demonstrate that ketosis leads to impairment of the GH signal transduction pathway. Low concentrations of IGF-I attenuate the negative feedback for $\mathrm{GH}$ secretion and increase $\mathrm{GH}$ release, which further promotes lipolysis of adipose tissue and augments fatty acids and BHB concentrations in blood. This vicious cycle further promotes the development of ketosis in dairy cows.

In summary, ketotic cows displayed high blood concentrations of fatty acids, BHB, and GH and low blood concentrations of IGF-I. The hepatic GH-mediated JAK2-STAT5 pathway was uncoupled in ketotic cows. In vitro, treatment of hepatocytes with high concentrations of fatty acids or BHB downregulated GHR1A expression and impaired the JAK2-STAT5 pathway, and these events subsequently inhibited the mRNA expression and secretion of IGF-I in calf hepatocytes (Figure 4G). These findings provide valuable information that increases our understanding of the molecular mechanisms of ketosis in dairy cows.

\section{ACKNOWLEDGMENTS}

This work was supported by the National Key Research and Development Program (Beijing, China; grant no. 2016YFD0501206) and the National Natural Science Foundation of China (Beijing, China; grant nos. 31360630, 31460681, 31472247, 31572581 and $31672621)$.

\section{REFERENCES}

Barclay, J. L., C. N. Nelson, M. Ishikawa, L. A. Murray, L. Kerr, T. R. Mcphee, E. E. Powell, and M. J. Waters. 2011. GH-dependent STAT5 signaling plays an important role in hepatic lipid metabolism. Endocrinology 152:181-192.

Bernier-Dodier, P., C. L. Girard, B. G. Talbot, and P. Lacasse. 2011. Effect of dry period management on mammary gland function and its endocrine regulation in dairy cows. J. Dairy Sci. 94:4922-4936.

Corbit, K. C., J. P. Camporez, J. L. Tran, C. G. Wilson, D. A. Lowe, S. M. Nordstrom, K. Ganeshan, R. J. Perry, G. I. Shulman, and M. J. Jurczak. 2017. Adipocyte JAK2 mediates growth hormoneinduced hepatic insulin resistance. JCI Insight 2:e91001. 
Deng, Q., G. Liu, L. Liu, Y. Zhang, L. Yin, X. Shi, J. Wang, X. Yuan, G. Sun, and Y. Li. 2015. BHBA influences bovine hepatic lipid metabolism via AMPK signaling pathway. J. Cell. Biochem. 116:1070-1079.

Dessauge, F., V. Lollivier, B. Ponchon, R. Bruckmaier, L. Finot, S. Wiart, E. Cutullic, C. Disenhaus, S. Barbey, and M. Boutinaud. 2011. Effects of nutrient restriction on mammary cell turnover and mammary gland remodeling in lactating dairy cows. J. Dairy Sci. 94:4623-4635.

Douglas, M. L., L. C. Marett, K. L. Macmillan, J. M. Morton, M. C. Hannah, A. D. Fisher, and M. J. Auldist. 2016. Associations of high and low milk protein concentrations with energy allocation, milk production, and concentrations of blood plasma metabolites and hormones in Holstein-Friesian cows. J. Dairy Sci. 99:1005710066.

Du, X., Z. Shi, Z. Peng, C. Zhao, Y. Zhang, Z. Wang, X. Li, G. Liu, and X. Li. 2017a. Acetoacetate induces hepatocytes apoptosis by the ros-mediated mapks pathway in ketotic cows. J. Cell. Physiol. 232:3296-3308.

Du, X., Y. Yang, C. Xu, Z. Peng, M. Zhang, L. Lei, W. Gao, Y. Dong, Z. Shi, X. Sun, Z. Wang, X. Li, X. Li, and G. Liu. 2017b. Upregulation of miR-181a impairs hepatic glucose and lipid homeostasis. Oncotarget 8:91362-91378. https://doi.org/10.18632/oncotarget .20523 .

Duffield, T. F., K. D. Lissemore, B. W. Mcbride, and K. E. Leslie. 2009. Impact of hyperketonemia in early lactation dairy cows on health and production. J. Dairy Sci. 92:571-580.

Egli, C. P., and J. W. Blum. 1998. Clinical, haematological, metabolic and endocrine traits during the first three months of life of suckling Simmentaler calves held in a cow-calf operation. Zentralbl. Veterinarmed. A 45:99-118.

Ehrhardt, S., and M. Schmicke. 2016. Isolation and cultivation of adult primary bovine hepatocytes from abattoir derived liver. EXCLI J. $15: 858-866$.

Elsasser, T., K. Klasing, N. Filipov, and F. Thompson. 2000. The metabolic consequences of stress: Targets for stress and priorities of nutrient use. Pages 77-110 in The Biology of Animal Stress: Basic Principles and Implications for Animal Welfare. CABI, Wallingford, UK.

Erikci, M. E., and G. S. Hotamisligil. 2016. Lipid signaling and lipotoxicity in metabolic inflammation: indications for metabolic disease pathogenesis and treatment. J. Lipid Res. 57:2099.

Fan, Y., X. Fang, A. Tajima, X. Geng, S. Ranganathan, H. Dong, M. Trucco, and M. A. Sperling. 2014. Evolution of hepatic steatosis to fibrosis and adenoma formation in liver-specific growth hormone receptor knockout mice. Front. Endocrinol. (Lausanne) 5:218.

Fenwick, M. A., R. Fitzpatrick, D. A. Kenny, M. G. Diskin, J. Patton, J. J. Murphy, and D. C. Wathes. 2008. Interrelationships between negative energy balance (NEB) and IGF regulation in liver of lactating dairy cows. Domest. Anim. Endocrinol. 34:31-44.

Geiger, A. J., C. L. Parsons, R. E. James, and R. M. Akers. 2016. Growth, intake, and health of Holstein heifer calves fed an enhanced preweaning diet with or without postweaning exogenous estrogen. J. Dairy Sci. 99:3995-4004.

Gross, J., H. A. van Dorland, F. J. Schwarz, and R. M. Bruckmaier. 2011. Endocrine changes and liver mRNA abundance of somatotropic axis and insulin system constituents during negative energy balance at different stages of lactation in dairy cows. J. Dairy Sci. 94:3484-3494

Hammon, H., and J. W. Blum. 1997. The somatotropic axis in neonatal calves can be modulated by nutrition, growth hormone, and Long-R3-IGF-I. Am. J. Physiol. 273:E130-E138.

Hanson, A. M., A. T. Ickstadt, D. J. Marquart, J. D. Kittilson, and M. A. Sheridan. 2017. Environmental estrogens inhibit mRNA and functional expression of growth hormone receptors as well as growth hormone signaling pathways in vitro in rainbow trout $(\mathrm{On}$ corhynchus mykiss). Gen. Comp. Endocrinol. 246:120-128.

Herdt, T. H. 2000. Ruminant adaptation to negative energy balance. Influences on the etiology of ketosis and fatty liver. Vet. Clin. North Am. Food Anim. Pract. 16:215-230.
Kobayashi, Y., C. K. Boyd, C. J. Bracken, W. R. Lamberson, D. H. Keisler, and M. C. Lucy. 1999. Reduced growth hormone receptor (GHR) messenger ribonucleic acid in liver of periparturient cattle is caused by a specific down-regulation of GHR 1A that is associated with decreased insulin-like growth factor I. Endocrinology 140:3947-3954

Kubista, M., J. M. Andrade, M. Bengtsson, A. Forootan, J. Jonak, K. Lind, R. Sindelka, R. Sjoback, B. Sjogreen, L. Strombom, A. Stahlberg, and N. Zoric. 2006. The real-time polymerase chain reaction. Mol. Aspects Med. 27:95-125.

Le Roith, D., C. Bondy, S. Yakar, J. L. Liu, and A. Butler. 2001. The somatomedin hypothesis: 2001. Endocr. Rev. 22:53-74.

Li, P., X. B. Li, S. X. Fu, C. C. Wu, X. X. Wang, G. J. Yu, M. Long, Z Wang, and G. W. Liu. 2012. Alterations of fatty acid $\beta$-oxidation capability in the liver of ketotic cows. J. Dairy Sci. 95:1759-1766.

Liu, L., X. Li, Y. Li, Y. Guan, Y. Song, L. Yin, H. Chen, L. Lei, J. Liu, and X. Li. 2014. Effects of nonesterified fatty acids on the synthesis and assembly of very low density lipoprotein in bovine hepatocytes in vitro. J. Dairy Sci. 97:1328-1335.

Lucy, M. C., H. Jiang, and Y. Kobayashi. 2001. Changes in the somatotrophic axis associated with the initiation of lactation. J. Dairy Sci. 84:E113-E119.

Lundberg, E., B. Kriström, B. Jonsson, and K. Albertsson-Wikland. 2015. Growth hormone (GH) dose-dependent IGF-I response relates to pubertal height gain. BMC Endocr. Disord. 15:84.

Mense, K., M. Meyerholz, M. G. Araujo, M. Lietzau, H. Knaack, C. Wrenzycki, M. Hoedemaker, and M. Piechotta. 2015. The somatotropic axis during the physiological estrus cycle in dairy heifersEffect on hepatic expression of GHR and SOCS2. J. Dairy Sci. 98:2409-2418

Morey, S. D., L. K. Mamedova, D. E. Anderson, C. K. Armendariz, E. C. Titgemeyer, and B. J. Bradford. 2011. Effects of encapsulated niacin on metabolism and production of periparturient dairy cows. J. Dairy Sci. 94:5090-5104.

Oetzel, G. R. 2004. Monitoring and testing dairy herds for metabolic disease. Vet. Clin. North Am. Food Anim. Pract. 20:651-674.

Parker, J. E., and E. M. Gaughan. 1988. Partial hepatic resection for treatment of a single liver abscess in a dairy heifer. Vet. Surg. 17:87-89.

Pfaffl, M. W. 2001. A new mathematical model for relative quantification in real-time RT-PCR. Nucleic Acids Res. 29:e45.

Piechotta, M., A. K. Sander, J. P. Kastelic, R. Wilde, M. Heppelmann, B. Rudolphi, H. J. Schuberth, H. Bollwein, and M. Kaske. 2012. Short communication: Prepartum plasma insulin-like growth factor-I concentrations based on day of insemination are lower in cows developing postpartum diseases. J. Dairy Sci. 95:1367-1370.

Radcliff, R. P., B. L. Mccormack, B. A. Crooker, and M. C. Lucy. 2003. Plasma hormones and expression of growth hormone receptor and insulin-like growth factor-I mRNA in hepatic tissue of periparturient dairy cows. J. Dairy Sci. 86:3920-3926.

Radcliff, R. P., B. L. Mccormack, D. H. Keisler, B. A. Crooker, and M. C. Lucy. 2006. Partial feed restriction decreases growth hormone receptor 1a mrna expression in postpartum dairy cows. J. Dairy Sci. 89:611-619.

Romero, C. J., E. Pinetwaddell, D. I. Sima, R. S. Miller, L. He, F. Wondisford, and S. Radovick. 2012. Insulin-like growth factor 1 mediates negative feedback to somatotroph $\mathrm{GH}$ expression via POU1F1/CREB binding protein interactions. Mol. Cell. Biol. 32:4258-4269.

Rukkwamsuk, T., M. J. H. Geelen, T. A. M. Kruip, and T. Wensing. 2000. Interrelation of fatty acid composition in adipose tissue, serum, and liver of dairy cows during the development of fatty liver postpartum 1. J. Dairy Sci. 83:52-59.

Sheehy, M. R., A. G. Fahey, S. P. Aungier, F. Carter, M. A. Crowe, and F. J. Mulligan. 2017. A comparison of serum metabolic and production profiles of dairy cows that maintained or lost body condition 15 days before calving. J. Dairy Sci. 100:536-547.

Shi, X., X. Li, D. Li, Y. Li, Y. Song, Q. Deng, J. Wang, Y. Zhang, H. Ding, and L. Yin. 2014. $\beta$-hydroxybutyrate activates the NF- $\kappa B$ signaling pathway to promote the expression of pro-inflammatory factors in calf hepatocytes. Cell. Physiol. Biochem. 33:920-932. 
Silva, P. R., K. S. Machado, S. D. Da, J. G. Moraes, D. H. Keisler, and R. C. Chebel. 2015. Effects of recombinant bovine somatotropin during the periparturient period on innate and adaptive immune responses, systemic inflammation, and metabolism of dairy cows. J. Dairy Sci. 98:4449-4464.

Silva, P. R., W. J. Weber, B. A. Crooker, R. J. Collier, W. W. Thatcher, and R. C. Chebel. 2017. Hepatic mRNA expression for genes related to somatotropic axis, glucose and lipid metabolisms, and inflammatory response of periparturient dairy cows treated with recombinant bovine somatotropin. J. Dairy Sci. 100:3983-3999.

Song, Y., N. Li, J. Gu, S. Fu, Z. Peng, C. Zhao, Y. Zhang, X. Li, Z. L. Wang, and X. Li. 2016. $\beta$-Hydroxybutyrate induces bovine hepatocyte apoptosis via an ROS-p38 signaling pathway. J. Dairy Sci. 99:9184-9198

Song, Y., X. Li, L. Yu, L. Na, X. Shi, H. Ding, Y. Zhang, X. Li, G. Liu, and W. Zhe. 2014. Non-esterified fatty acids activate the ROS-p38-p53/Nrf2 signaling pathway to induce bovine hepatocyte apoptosis in vitro. Apoptosis 19:984-997.
Thimmarayappa, J., J. Sun, L. E. Schultz, P. Dejkhamron, C. Lu, A. Giallongo, J. L. Merchant, and R. K. Menon. 2006. Inhibition of growth hormone receptor gene expression by saturated fatty acids: Role of Kruppel-like zinc finger factor, ZBP-89. Mol. Endocrinol. 20:2747-2760

Thissen, J. P., J. Ketelslegers, and L. E. Underwood. 1994. Nutritional regulation of the insulin-like growth factors. Endocr. Rev. 15:80-101.

Xu, C., S. Shu, C. Xia, P. Wang, Y. Sun, C. Xu, and C. Li. 2015 a. Mass spectral analysis of urine proteomic profiles of dairy cows suffering from clinical ketosis. Vet. Q. 35:133-141.

Xu, C., Q. Xu, Y. Chen, W. Yang, X. Cheng, H. Yu, K. Zhu, T. Shen, and Z. Zhang. 2015b. The relationship between Fibroblast Growth Factor-21 and characteristic parameters related to energy balance in dairy cows. BMC Vet. Res. 11:271.

Yamdagni, S., and L. H. Schultz. 1970. Fatty acid composition of blood plasma lipids of normal and ketotic cows. J. Dairy Sci. 53:1046-1050. 